\title{
Fundamentos ideológicos e normativos do "Programa Escola sem Partido" e seus desdobramentos na educação brasileira
}

\author{
Ideological and normative foundations of the "Escola sem Partido Program" \\ and its developments in Brazilian education \\ Fundamentos ideológicos y normativos del "Programa Escola sem Partido" \\ y sus desarrollos en la educación brasileña
}

Fernanda Motta de Paula Resende ${ }^{1}$ Universidade Estadual Paulista "Júlio de Mesquita Filho"

Glariston Resende ${ }^{2}$ Tribunal de Justiça do Estado de São Paulo

Julio Cesar Torres ${ }^{3}$ Universidade Estadual Paulista "Júlio de Mesquita Filho"

Maria Denise Guedes ${ }^{4}$ Universidade Estadual Paulista "Júlio de Mesquita Filho"

Resumo: Este artigo apresenta os resultados da pesquisa sobre os fundamentos ideológicos e normativos do "Programa Escola sem Partido" - Projeto de Lei (PL) n 867/2015. Com base em análise documental e bibliográfica, foi possível identificar as fragilidades dos fundamentos ideológicos do PL, suas inconsistências lógico-teóricas e como retomam valores seculares de nossa sociedade. Buscam apoio no arcabouço jurídico e político-institucional ressignificando preceitos jurídicos, outrora consolidados, com o objetivo de desregulamentar práticas democráticas, impondo à educação grilhões autoritários.

Palavras-chave: Educação. Políticas Educacionais. Programa Escola Sem Partido. Censura.

Abstract: This article presents the results of the research on the ideological and normative foundations of the "Escola Sem Partido Program" - Bill of Law (PL) n 867/2015. Based on documentary and bibliographic analysis, it was possible to identify the weaknesses of the ideological foundations of the PL, its logical-theoretical inconsistencies and how they take up secular values in our society. They seek support in the legal and political-institutional framework, re-signifying legal precepts, once consolidated, with the objective of deregulating democratic practices, imposing authoritarian fetters on education.

\footnotetext{
${ }_{1}$ Doutora em Educação. Professora do Departamento de Educação da UNESP de São José do Rio Preto, São Paulo, Brasil. E-mail: fernanda.resende@unesp.br. Lattes: http://lattes.cnpq.br/5480864234175333. ORCID: http://orcid.org/0000-0002-7435-6937.

2 Mestre em Política Públicas. Juiz Titular da $1^{\text {a }}$ Vara Criminal e da Infância e Juventude de Fernandópolis, Fernandópolis, São Paulo, Brasil. E-mail: glaristonresende@yahoo.com.br. Lattes: http://lattes.cnpq.br/4862844537131345. ORCID: https://orcid.org/o000-0003-2513-0058.

${ }^{3}$ Doutor em Sociologia. Professor do Departamento de Educação da UNESP de São José do Rio Preto e do Programa de Pós-Graduação em Educação da UNESP de Marília, São Paulo, Brasil. E-mail: julio.torres@unesp.br. Lattes: http://lattes.cnpq.br/7328873141659824. ORCID: https://orcid.org/0000-0002-1002-0078.

${ }_{4}^{4}$ Doutora em Educação. Professora do Departamento de Educação da UNESP de São José do Rio Preto, São Paulo, Brasil. E-mail: md.guedes@unesp.br. Lattes: http://lattes.cnpq.br/9443992129856023. ORCID: https://orcid.org/0000-0001-7206-2655.
} 
Keywords: Education. Educational Policies. Escola Sem Partido Program. Censorship.

Resumen: Este artículo presenta los resultados de la investigación sobre los fundamentos ideológicos y normativos del "Programa Escola Sem Partido" - Proyecto de Ley $(\mathrm{PL}) \mathrm{n}^{\circ}$ 867/2015. A partir del análisis documental y bibliográfico, fue posible identificar las debilidades de los fundamentos ideológicos del PL, sus inconsistencias lógico-teóricas y cómo asumen los valores seculares en nuestra sociedad. Buscan apoyo en el marco legal y político-institucional, resignificando los preceptos legales, una vez consolidados, con el objetivo de desregular las prácticas democráticas, imponiendo trabas autoritarias a la educación.

Palabras clave: Educación. Políticas educativas. Programa Escola Sem Partido. Censura.

Recebido em: 11 de agosto de 2021

Aceito em: 27 de setembro de 2021

\section{Introdução}

Passadas mais de duas décadas de promulgação da Lei de Diretrizes e Bases da Educação Nacional - LDBEN n ${ }^{\circ}$ 9.394/96, e com a acelerada desconstrução dos princípios democráticos conquistados por meio das lutas pela redemocratização do Estado brasileiro nos anos de 1980, presenciamos o distanciamento da sociedade brasileira da mobilização e da participação social.

Frente a um inovador e singular golpe de Estado, enfrentamos ações governamentais truculentas que visam aniquilar as incipientes experiências democráticas participativas, primando, sobretudo, pela intensificação do processo de destruição da escola pública, pelo silenciamento do professorado e pela desarticulação dos mecanismos e espaços democráticos da sociedade brasileira, tais como a extinção ou esvaziamento de conselhos de áreas de políticas públicas. Um exemplo concreto que vivenciamos desse silenciamento é o projeto de lei, o PL n ${ }^{\circ}$. 867/2015 - "Programa Escola sem Partido", fruto do contramovimento de cunho conservador, vencedor nesta lavra da história, com a eleição do Presidente Jair Messias Bolsonaro.

Nesse sentido, o objetivo da pesquisa foi analisar os fundamentos ideológicos e normativos do "Programa Escola sem Partido" - Projeto de Lei (PL) nº 867/2015, frente ao contexto dos graves fatos políticos desencadeados no Brasil após o golpe de Estado sofrido pela presidenta Dilma Roussef. Para alcançar tal objetivo, o estudo teve como base uma análise documental tomando como objeto o Projeto de Lei 867/2015 
(Programa Escola sem Partido), bem como por meio de pesquisa bibliográfica que contribuiu para a análise conceitual do projeto.

A partir dos resultados da pesquisa foi possível identificar as fragilidades dos fundamentos ideológicos do PL, suas inconsistências lógico-teóricas e como retomam valores seculares de nossa sociedade, de forma singela e descompromissada. Foi possível demonstrar, também, como estes fundamentos ideológicos buscam apoio no arcabouço jurídico e político-institucional ressignificando preceitos jurídicos, outrora consolidados, com o objetivo de desregulamentar práticas democráticas, impondo à educação grilhões autoritários. Portanto, a partir dos resultados desse estudo pretendese contribuir com o debate sobre as políticas educacionais brasileira, no atual contexto marcado pelo avanço do conservadorismo e do fundamentalismo religioso que passou a orientar as decisões políticas no Brasil e, em especial, a educação brasileira.

\section{Da marcha democrática ao silenciar autoritário}

De acordo com Arelaro (2000), é no início dos anos de 1980 que os movimentos sociais começam a se reorganizar em entidades e instituições, das quais se destacam, no campo da educação, dentre outras, a Associação Nacional dos Docentes de Ensino Superior (ANDES), Associação Nacional de Educação (ANDE) e a Confederação dos Professores do Brasil (CPB), esta última depois organizada em Confederação Nacional dos Trabalhadores em Educação (CNTE). Nesse período, foram realizadas as Conferências Brasileiras de Educação, as quais reuniram partidos políticos, educadores, intelectuais, estudantes e sindicatos, motivados pela convocação da Assembleia Nacional Constituinte, que discutiria uma nova Constituição para o Brasil. Nesse cenário, é também criado o Fórum Nacional pela Constituinte, mais tarde Fórum Nacional em Defesa da Escola Pública (FNDEP), o qual possibilitou intensas mobilizações no processo de elaboração que culminou com a aprovação, na Constituição da República Federativa do Brasil, em 1988, do Título VIII - Da Ordem Social, Capítulo III, Seção I - Da Educação (artigos 205 a 214).

A mobilização social em favor da educação pública, como esclarece Bollmann (2010), estava expressa na composição do FNDEP, que, em 1996, contava com mais de trinta entidades, entre elas: Associação Brasileira de Imprensa (ABI), Associação Nacional de Educação (ANDE), Sindicato Nacional dos Docentes das Instituições de Ensino Superior (ANDES-SN), Associação Nacional pela Formação dos Profissionais da Educação (ANFOPE), Associação de Dirigentes das Instituições Federais de Ensino Superior (ANDIFES), Associação Nacional de Política e Administração da Educação (ANPAE), Associação Nacional de Pesquisa e Pós-Graduação em Educação (ANPEd), Conferência 
Nacional dos Bispos do Brasil (CNBB), Confederação Nacional dos Trabalhadores em Educação (CNTE), Confederação Nacional dos Trabalhadores em Estabelecimentos de Ensino (CONTEE), Conselho de Reitores das Universidades Brasileiras (CRUB), Central Única dos Trabalhadores (CUT), Federação de Sindicatos de Trabalhadores das Universidades Brasileiras (FASUBRA), Movimento dos Trabalhadores Rurais Sem-Terra (MST), Sindicato Nacional dos Servidores Federais da Educação Básica e Profissional (SINASEFE), Ordem dos Advogados do Brasil (OAB), União Nacional dos Dirigentes Municipais de Educação (UNDIME), União Nacional dos Estudantes (UNE) e União Brasileira de Estudantes Secundaristas (UBES), demonstrando a composição política suprapartidária e pluralista do Fórum.

Para Saviani (2007), os processos de mobilização da sociedade brasileira, tanto no Fórum como nas Conferências, demarcaram um momento de maturidade para a reflexão acadêmica, sendo determinante para a qualidade da educação brasileira, expressa pela significativa produção científica nesse campo, e com notória influência dos educadores na proposta da Constituinte de 1988 e, posteriormente, na proposta de uma nova LDBEN.

E, assim, essa intensa mobilização popular, ao menos no plano normativo, alcançou grandes conquistas democráticas no texto maior da República. A Constituição Federal de 1988 trouxe importantes nortes principiológicos em que a sociedade deveria se pautar. Apenas para exemplificar, citamos:

a educação seria promovida e incentivada com a colaboração da sociedade (art. 205); ii) O ensino será ministrado com base nos seguintes princípios (art. 206, caput): II - liberdade de aprender, ensinar, pesquisar e divulgar o pensamento, a arte e o saber; III - pluralismo de ideias e de concepções pedagógicas, e coexistência de instituições públicas e privadas de ensino; VI - gestão democrática do ensino público, na forma da lei; VII - garantia de padrão de qualidade; iii) as universidades gozam de autonomia didático-científica (BRASIL, 1988).

Faltava concretizar o sopro democrático que a Carta de 1988 era arauta. Para Arelaro (2000), se na década de 1990 a sociedade brasileira expressava o desejo da implementação dos direitos sociais recém-conquistados, por meio de uma intensa mobilização social, seus primeiros anos ficaram marcados pelos discursos e propostas sobre a função do Estado na organização econômica e nas áreas sociais, sobretudo por conta do projeto de caráter neoliberal do então Presidente da República, Fernando Collor de Mello, que prometia urgência nas reformas do Estado, supostamente visando colocar o Brasil na era da "modernidade".

Por não haver um projeto consistente de intervenção social, a educação, mesmo sendo considerada nos discursos políticos como expressão da cidadania, não foi 
prioridade no decorrer do governo Collor, posto que, ainda, para a autora, "não havia propostas concretas por parte do governo capazes de mobilizar a sociedade para ações mais abrangentes em educação" (ARELALO, 2000, p. 96). Muitas dessas propostas, erigidas muito mais dos movimentos sociais em prol da educação, não se transformaram, imediatamente, em ações concretas do governo, cuja preocupação era, em maior escala e em caráter prioritário, implementar uma reforma do Estado.

Ao mesmo tempo que os educadores e as entidades discutiam essas propostas no Fórum e nas Conferências, o Ministério da Educação (MEC) executava programas financiados pelo Banco Mundial (BM), dirigidos ao ensino técnico e ao ensino fundamental, cujas propostas oficiais para a qualidade da educação "eram estreitamente vinculadas aos objetivos dos projetos internacionais, entre eles, a criação de uma sistemática de avaliação para medir o impacto desses programas no desempenho escolar dos municípios atingidos" (FONSECA, 2009, p.164-165).

No Governo FHC (1995-2002), presenciamos paulatino sucateamento da universidade pública, com contingenciamentos de recursos, gerando insatisfações e inúmeras e longas greves de professores e alunos no período. Se no campo material, de recursos humanos e financeiros, não houve atenção à educação, no campo ideológico-normativo também pouco se adiantou em termos de regulamentação da gestão democrática, plural e com liberdade de cátedra, determinada na Constituição. Apesar da importante publicação da LDBEN/1996 para a área da educação, pouco significou em termos de regulamentação em prol da consolidação de uma verdadeira gestão democrática da escola pública, não protegendo as instituições de ensino de eventual retrocesso autoritário, que não tardaria.

Nos governos petistas (2003-2016), conforme aponta Frigotto (2017, p.22), “os grandes empresários e o capital financeiro não foram confrontados, pelo contrário, continuaram ganhando até mais do que no governo Fernando Henrique Cardoso, especialmente no período de forte expansão da economia brasileira”. Em que pese os consideráveis avanços em termos de recursos financeiros para a área, com a expansão das universidades públicas, criação dos Institutos Federais de Educação, Ciência e Tecnologia, criação de piso salarial para a classe docente, criação de financiamentos para o ensino superior, criação de piso mínimo em percentil de Produto Interno Bruto - PIB para o financiamento da educação e etc., no plano ideológico-normativo também pouco se avançou em termos de regulamentação da gestão democrática da educação e da escola, possibilitando o avanço autoritário que se estabeleceria na sequência.

Nessa perspectiva, a partir de 2015 , assistimos, entre outras iniciativas, à tramitação no Congresso Nacional brasileiro de um deletério projeto de lei, o PL nº. 876/2015 - 
"Programa Escola sem Partido", fruto do contramovimento direitista, vencedor nesta lavra da história, com a eleição do Presidente Jair Messias Bolsonaro, após a derrocada sofrida pela esquerda do país. Segundo Manhas (2016, p. 19-20),

A proposta foi apresentada em forma de projeto pela primeira vez no Estado do Rio de Janeiro, pelo deputado Flávio Bolsonaro. A segunda vez no Estado do Rio de Janeiro, pelo vereador Carlos Bolsonaro - ambos filhos do deputado federal Jair Bolsonaro. E tal proposta já se espalhou por diversas câmaras municipais e assembleias legislativas. Em âmbito nacional, o deputado Izalci (PSDB/DF) apresentou o PL 867/2015 à Câmara Federal, que altera a Lei de Diretrizes e Bases da Educação Nacional.

Até este quadrante da história brasileira, a direita se colocava em defesa intransigentemente às liberdades, todas elas, sejam individuais, sejam coletivas, defendendo, inclusive, as liberdades das profissões, principalmente a liberdade de cátedra e a da difusão da ciência como todo. Porém, a esquerda, se colocava como defensora da igualdade como princípio fundante e, portanto, sempre aceitou a mitigação das liberdades, desde que, levasse à igualização dos indivíduos. No entanto, os papéis parecem ter sido invertidos, defendendo a direita a mitigação da liberdade de cátedra e da difusão do conhecimento e das ciências, porém, diferentemente da esquerda, sem qualquer finalidade igualitária, defendendo-se pura e exclusivamente a retirada de um conhecimento e forma de pensar dos bancos das escolas públicas brasileiras.

Essa inversão se explica tendo em vista que, antes se defendia intransigentemente as liberdades de cátedra e da difusão das ciências por se ter a tranquilidade do respaldo do Estado policialesco, que tratava de extirpar a difusão indesejada de tal ou qual ideologia nas ciências, mediante a repressão policial. Portanto, formalmente, fora do âmbito científico, tinha-se a possibilidade de impor à fórceps sua ideologia com disciplinas deliberadamente formatadas como a Educação Moral e Cívica (para o primeiro grau), Organização Social e Política do Brasil (OSPB, para o segundo grau), e Estudos dos Problemas Brasileiros (EPB, no ensino de nível superior).

Não havendo, momentaneamente, ante à conjuntura internacional, mais espaço para o Estado policialesco de outrora e, sendo a imposição de disciplinas como a Educação Moral e Cívica frontalmente contrária aos princípios da liberdade de cátedra e da livre difusão da ciência, utiliza-se do formalismo das proposituras jurídicas para encobertar a realidade concreta, vendendo-se a ideia da libertação de nossos filhos da doutrinação ideológica, a ideia de que os defensores das premissas do "Escola sem Partido" sejam os defensores da

\footnotetext{
${ }^{5}$ Em consulta realizada no site da Câmara dos Deputados, em 14/10/2020 às 10:38h, o referido projeto de lei encontra-se tramitando no regime ordinário sujeito à apreciação do plenário a qualquer momento https://www.camara.leg.br/proposicoesWeb/fichadetramitacao?idProposicao=1050843.
} 
verdadeira liberdade, sendo os seus opositores, defensores da manutenção do status quo, representado pela doutrinação ideológica.

Em síntese, vende-se a ideia da verdadeira liberdade nas escolas, comprada facilmente, caso não se descortine a falácia do silogismo vendido.

\section{A ideologia e a norma jurídica}

Por utilizar a força para dominação e pacificação social, o Estado lança mão de dois importantes instrumentais que atuam no plano da consciência social, o direito e as ideologias. As ideologias, enquanto "um conjunto de ideias e de valores respeitantes à ordem pública e tendo como função orientar os comportamentos políticos coletivos" (STOPPINO, 2004, p. 585), tem dois papeis importantíssimos: o de convencimento e arregimentação social e o de condução do aparelho de Estado, no poder e fora do poder. São os arquétipos teóricos que legitimam as ações estatais e, portanto, agasalham-se no direito. O direito, por seu turno, é um instrumental de dominação e pacificação social que tem como fim último a prescrição de comportamentos sociais esperados, em regra, sob pena do atuar violento por parte do Estado.

Havendo uma mudança da base econômica da sociedade, uma mudança do Estado, toda ela lastreada em ideologias novas ou velhas, em que se espera comportamento distinto social, por lógico, o direito espelhará estas mudanças, exigindo do cidadão uma nova postura. A lei, entendida em seu sentido lato sensu, abarcando todos os comandos normativos legais editados e promulgados pelo Estado, bem como os marcos normativos internacionais por ele reconhecidos, é um dos instrumentais, produto de dominação, utilizado para a aplicação do direito, talvez o de maior importância em Estados de Direito. Entretanto, nos Estados despóticos, autoritários, totalitários, em maior ou menor monta, paulatinamente o direito vai se confundindo com a vontade do soberano, ou seja, na medida em que o rigor autoritário vai se adensando, os preceitos legais normativos vão se arrefecendo, perdendo-se, gradativamente, a centralidade que a lei tinha na aplicação do direito, quando na fase do Estado de Direito.

Segundo Reale (2002), na medida do aumento do rigor autoritário, a estrutura proposicional enunciativa de uma forma de organização, ou de condução da norma jurídica, vai perdendo sua objetividade e obrigatoriedade, considerando que sobre sua aplicação vai pesando uma insegura e volátil vontade do soberano, ceifando, aos poucos, a segurança que a norma poderia trazer.

O que efetivamente caracteriza uma norma jurídica, de qualquer espécie, é o fato de ser uma estrutura proposicional enunciativa de uma forma de 
organização ou de conduta, que deve ser seguida de maneira objetiva e obrigatória. Dizemos que a norma jurídica é uma estrutura proposicional porque o seu conteúdo pode ser enunciado mediante uma ou mais proposições entre si correlacionadas, sendo que o significado pleno de uma regra jurídica só é dado pela integração lógico-complementar das proposições que nela se contêm. Dizemos, outrossim, que a regra jurídica enuncia um dever ser de forma objetiva e obrigatória, porquanto, consoante já foi exposto em aulas anteriores, é próprio do Direito valer de maneira heterônoma, isto é, com ou contra a vontade dos obrigados, no caso das regras de conduta, ou sem comportar alternativa de aplicação, quando se tratar de regras de organização (REALE, 2002, p. 95-96).

Nessa perspectiva, a lei é o principal instrumental de aplicação do direito, sendo ela uma síntese, produto dos fatores reais do poder e da dominação. Ao concluir que a lei é uma síntese da mediação dos fatores reais do poder, temos que lembrar de que quanto mais democrático e estável é o tecido social, menos a síntese legal representará a vontade exclusiva de um grupo ou ator social. Neste contexto, as mudanças do texto, ou interpretativa das normas, são feitas de forma mais paulatina, a depender da posição momentânea dos fatores reais do poder da sociedade, sociedade esta com tradição, instituições e demais sínteses sociometabólicas sólidas a impedir a imposição abrupta da vontade de um grupo ou sujeito social em prejuízo da síntese legal já reinante naquele momento.

Razão outra não houve para a concepção da teoria dos checks and balances system ${ }^{6}$, em que, visando justamente à diminuição do poder relativo do soberano, houve a partição do poder de forma tripartite, em que os poderes executivo, judiciário e legislativo foram conferidos a autoridades distintas, tendo cada qual, dentro de sua competência préestabelecida, o poder-dever de contrabalancear o poder das demais autoridades, de modo que o resultado de suas ações não represente unicamente a vontade exclusiva do soberano, permitindo-se, em maior ou menor grau, a depender de cada Estado e tempo histórico por ele vivido, representar a resultante da vontade do povo.

Ao contrário, em países, como o Brasil, em que o tecido social é extremamente heterogêneo, com constantes ataques às leis vigentes, às instituições, à democracia, em que a plutocracia, não raramente, para manter a sua posição privilegiada, atua para desestabilizar a parte legal referente à democracia, aos ganhos sociais das demais classes sociais, a lei não tem a centralidade daqueles outros países, e não há a segurança esperada do marco legal, sempre em constante mudança, tanto de texto, como de interpretação, quando, não raramente, são as leis excepcionadas.

\footnotetext{
${ }^{6}$ Princípio jurídico de controle de poder, na divisão de poderes do Estado, em que cada Poder de Estado possui poderes (mecanismos) para limitar a atuação plena e autoritária dos outros Poderes de Estado, criando uma ambiência de compartilhamento de poder, essencial para a democratização do referido Estado. Verdadeiro controle recíproco entre os Poderes do referido Estado.
} 
Nos Estados de Direito, nos períodos de normalidade social, é por meio da lei, como instrumental principal, que os fatores reais do poder impõem, ou tentam impor, uma forma de conduta, sancionando os comportamentos sociais em contrário dos sujeitos sociais dissonantes. A lei, como instrumental principal de um Estado de Direito, atrai a atenção de todos os sujeitos sociais envolvidos na criação e aplicação do direito, prendendo seus atuares, constituindo o centro da arena política, sendo o ponto de partida e de chegada de seus discursos, com toda a carga ideológica envolvida, de arregimentação e convencimento para sua criação, interpretação e aplicação.

Num Estado de Direito, a lei representa todo o ideal de proteção dos administrados e de modulação do poder do soberano, visando estabelecer as regras sociais de antemão, para que administrados não sejam surpreendidos a posteriori, como também para limitar a atuação do soberano, que da lei não deve se afastar, o que trará maior liberdade a todos. Esta ideia sintetiza o princípio da legalidade.

O princípio da legalidade nasceu do anseio de estabelecer na sociedade humana regras permanentes e válidas, que fossem obras da razão, e pudessem abrigar os indivíduos de uma conduta arbitrária e imprevisível da parte dos governantes. Tinha-se em vista alcançar um estado geral de confiança e certeza na ação dos titulares do poder, evitando-se assim a dúvida, a intranquilidade, a desconfiança e a suspeição, tão usuais onde o poder é absoluto, onde o governo se acha dotado de uma vontade pessoal soberana ou se reputa legibus solutus e onde, enfim, as regras de convivência não foram previamente elaboradas nem reconhecidas. A legalidade, compreendida pois como a certeza que têm os governados de que a lei os protege ou de que nenhum mal portanto lhes poderá advir do comportamento dos governantes, será então sob esse aspecto, como queria Montesquieu, sinônimo de liberdade (BONAVIDES, 1997, p. 112).

Se se pretende mudar um comportamento social, devem os fatores reais do poder, não como instrumento único, porém como instrumento principal, voltarem-se para o marco legal, para darem-lhe nova roupagem (revogando, ab-rogando, derrogando e etc.), ou mantendo-se o mesmo figurino, para darem-lhe novo sentido (alterações interpretativas, ampliativas, reducionistas, conceituais etc.).

Isso explica a ferrenha batalha em torno do marco legal, sendo constantes as mudanças legais, com árduo trabalho dos legisladores, a partir da mudança de posições dos fatores reais de poder e, até mesmo, as constantes mudanças interpretativas de uma mesma norma.

Como, ainda, vivemos em uma sociedade que cultua o instrumental legal como instrumento da liberdade, esta crença implica em que é em torno da lei que as discussões comportamentais partem, pois sua aplicação pressupõe o que chamamos de legitimidade, sem a qual soçobra toda a crença no Estado de Direito. Nesse sentido, legitimidade é: 
[...] um atributo do Estado, que consiste na presença, em uma parcela significativa da população, de um grau de consenso capaz de assegurar a obediência sem a necessidade de recorrer ao uso da força, a não ser em casos esporádicos. É por esta razão que todo poder busca alcançar consenso, de maneira que seja reconhecido como legítimo, transformando a obediência em adesão. A crença na Legitimidade é, pois, o elemento integrador na relação de poder que se verifica no âmbito do Estado ( LEVI, 2000, p. 675).

Assim, a lei pauta o discurso da aplicação do direito, sendo ela o ponto de partida das digressões interpretativas, mesmo quando o direito aplicado dela se afasta completamente (ex., o estado de exceção), pois todo poder busca o consenso para a sua manutenção. Portanto, depois de perder o monopólio do Poder central por mais de uma década, a ala conservadora, agora restituída ao centro de poder e decisão, volta-se à lei para a legitimação da mudança comportamental que visa implantar.

\section{A fragilidade dos fundamentos ideológico-normativos do PL 867/2015}

O Programa "Escola sem Partido" - Projeto de Lei (PL) nº 867/2015 demonstra sua contradição já nos princípios que visa atender:

Art. $2^{\circ}$. A educação nacional atenderá aos seguintes princípios:

I - neutralidade política, ideológica e religiosa do Estado;

(...)

VII - direito dos pais a que seus filhos recebam a educação moral que esteja de acordo com suas próprias convicções;

Art. $3^{\circ}$. São vedadas, em sala de aula, a prática de doutrinação política e ideológica bem como a veiculação de conteúdo ou a realização de atividades que possam estar em conflito com as convicções religiosas ou morais dos pais ou responsáveis pelos estudantes.

Observam-se as contradições nas ideais basilares, ao tentar fazer crer, primeiro, que o Estado se conduz sem qualquer influência política, ideológica ou religiosa, portanto, que existe algum tipo de Estado neutro nestes aspectos, premissa esta, que, sem baixo tirocínio, pode ser prontamente rechaçada, na medida em que Estado assim nunca existiu, não existe e, tampouco, existirá. Segundo, que é possível assegurar aos pais uma educação moral de seus filhos que esteja de acordo com suas próprias convicções, dada a gama de divergências de pensamento. Terceiro, menciona o referido projeto de lei o absurdo de que é vedada "a veiculação de conteúdos ou a realização de atividades que possam estar em conflito com as convicções religiosas ou morais dos pais ou responsáveis pelos estudantes", como se fosse de possível aferição na prática.

Ademais, a inconsistência ideológica do Projeto ainda gravita em torno de duas outras proposituras: o que é influência política? Como um Estado se conduz sem influência política? 
O próprio Estado nasceu da política, mantém-se como organização política da sociedade, e perdurará tão somente pela política, de modo que é absurdo se pensar nesta propositura de que o Estado brasileiro se conduzirá sem influências políticas. A política é todo o atuar humano voltado às relações entre os humanos, voltado às integrações entre os seres, voltado às satisfações de nossas demandas pelos outros. Onde há dois humanos, política há, razão pela qual, há milênios, já concluiu Aristóteles que o homem é um animal político. Tudo no Estado, por ser um ambiente de complexas relações entre os cidadãos, por ser palco das lutas de classe, necessita de complexo atuar político, de modo que é uma mistificação de má-fé tentar vender a ideia de que o Estado pode atuar, em qualquer de suas áreas, sem influências de cunho político.

Desse modo, na formulação das políticas educacionais, não há nada que não esteja sob forte atuar político. Tudo neste âmbito é fruto de escolhas políticas, em que o grupo de poder dominante consegue impor suas escolhas políticas sobre os demais, levando à condução da educação nacional para um ou outro lado. Neste campo residem fortes influências políticas, em que o que se tem é o fruto deste atuar político de todos os sujeitos sociais responsáveis, de modo que é aviltante a tentativa de ocultação desta realidade. Ora, se existe escola pública, é uma escolha política; quantos alunos por sala, a forma de contratação do professor, o salário dos professores, as suas formações, a forma de escolha dos diretores escolares, a obrigatoriedade ou não da inclusão dos alunos com deficiência, os currículos nacionais, e etc., até chegar no próprio "Programa Escola sem Partido", tudo é uma resultante de atuação política.

Para a implementação da ideologia conservadora nos marcos legais da educação nacional, o Programa Escola sem Partido, visa, fundamentalmente, silenciar as ideologias opositoras, penalizando quem as defende. Mesmo que a jurisprudência pátria desmascare a infâmia deste projeto e, portanto, aponte as impossibilidades de aplicação e fiscalização, já haveria um ganho incomensurável com a promulgação da lei, que configura em sua própria existência, em um instrumento legal para o cerceamento e controle dos professores brasileiros. Ou seja, a vigência, em si, da lei, seria um enorme retrocesso, pois permitiria ser os professores processados e coagidos, sob o respaldo legal, e, ainda, com possibilidade de vitória dos atores conservadores.

Em um país com poucas oportunidades de mobilidade social devido as desigualdades historicamente vivenciadas, não é difícil visualizar que a maioria dos sujeitos sociais que aplicarão esta lei serão frutos da elite social brasileira, ou cooptados por seus valores, de modo que terão fatalmente afinidade de pensamentos sobre o que se considerará ou não político, moral, ideológico ou religioso. 
O PL 867/2015, destina-se, principalmente, a controlar os professores da educação básica do ensino público, não visando à educação básica do ensino particular, tampouco, ao ensino superior. Os $\$ \S 1^{\circ}$ e $2^{\circ}$ do art. $3^{\circ}$ deixam claro que a lei não se destina às escolas particulares, de modo que estas podem ficar como estão, ensinando o que bem entendem por política, moral, ideologia ou religião.

Em síntese, trata-se de um projeto que visa alcançar a formação da massa pobre dos cidadãos em geral, resguardando a liberdade de informação dos filhos das elites, na medida em que para estes a própria posição social, em maior ou menor tempo, moldará suas formações e atuares, como já observaram Nogueira, Romanelli e Zago (2000). Justamente as instituições que mais detêm respaldo jurídico para se defender, ou respaldo jurídico para defenderem seus professores, estarão a salvo de quaisquer agruras advindas da lei. Protege-se a formação da elite, para massificar convenientemente a formação da massa trabalhadora, pois estes estudam em escolas públicas, que não têm qualquer respaldo jurídico, e não possibilita qualquer respaldo jurídico ou financeiro aos seus professores, únicas vítimas desse projeto de lei.

\section{Inconstitucionalidade do PL 867/2015}

Mesmo desconsiderando tudo o que fora dito acima, isto é, que realmente se pudesse separar o que é doutrinação ideológica ou não, o que é doutrinação política ou não, o que é atentatório às convicções morais e religiosas de todas as famílias brasileiras, ainda assim, esse projeto de lei é, sobretudo, inconstitucional.

Muitas vezes, na seara jurídica, por tudo o que foi dito anteriormente, principalmente por representar a área um ferramental de dominação política, impera-se a hipocrisia em que os interessados levam ao debate ao nível do dever-ser, da aparência, portanto, não possibilitando a descida ao ser, a correlação e influência que a aplicação de uma norma tem com a realidade. Levando a discussão meramente ao dever-ser, percebe-se que a lei é inconstitucional, na medida em que se atenta a inúmeros dispositivos constitucionais.

Atenta-se, desde seu início, a um dos fundamentos da República, que é o princípio da cidadania (art. $1^{\circ}$, II, da $\mathrm{CF} / 88$ ), na medida em que para se chegar à cidadania plena, para permitir que a pessoa seja um cidadão pleno, deve ser possibilitada a ele toda informação, não havendo qualquer ocultamento de qualquer pensamento. Assim, não se pode censurar o que se considera politicamente, ideologicamente, religiosamente ou moralmente incorreto, e que não se pode ser dito em sala de aula. É preferível que o cidadão receba ao longo de sua vida as várias cargas ideológicas correntes para que, em sua maturidade, possa seguir plenamente e conscientemente seu caminho da cidadania, do 
que formar um ambiente previamente censurado que filtre o que o cidadão possa ou não conhecer, permitindo o conhecimento de um único caminho.

Aqui há de ser ressaltado que, em que pese a esquerda ser tradicionalmente ligada aos interesses dos professores da rede básica de ensino, não é verdade que todos os professores, nem mesmo a maioria, são de esquerda, muito menos que são marxistas. Desse modo, a própria pluralidade de pensamentos, a própria pluralidade de formações e vivencias de cada professor, já possibilita ao aluno o contato com uma ou outra forma de pensar, opinião política, valores sociais e morais, que serão essenciais à formação futura do ser humano. Portanto, não é correto afirmar que há uma preponderância do professor sobre os outros formadores, em especial aos pais, de modo que haverá canais outros que farão o contrapeso, permitindo uma escolha ao formando com mais elementos, em detrimento a qualquer tipo de censura prévia.

Não se olvide que o direito à cidadania também compõe uma das finalidades da educação do cidadão, e, nos termos do art. 205 da CF/88, "a educação, direito de todos e dever do Estado e da família, será promovida e incentivada com a colaboração da sociedade, visando ao pleno desenvolvimento da pessoa, seu preparo para o exercício da cidadania e sua qualificação para o trabalho".

Considerando o prisma do aluno, já para o plano do trabalhador, do educador, tem ele a liberdade de cátedra: "Art. 206. O ensino será ministrado com base nos seguintes princípios: ... II - liberdade de aprender, ensinar, pesquisar e divulgar o pensamento, a arte e o saber”. Liberdade de cátedra não somente decorrente da profissão docente, em que pese ser para esta mais essencial do que para qualquer outra, porém decorrente de toda e qualquer manifestação intelectual e científica, sendo esta última direito fundamental individual de qualquer pessoa, nos termos do art. $5^{\circ}$, IX, da $\mathrm{CF} / 88$.

Além da liberdade de cátedra, do direito individual fundamental da liberdade de manifestação intelectual e científica, não pode o professor, como não pode qualquer outro cidadão, exercendo ele qualquer profissão que seja, ser penalizado por manifestar seu pensamento (direito fundamental do art. $5^{\circ}, \mathrm{IV}$, da $\mathrm{CF} / 88$ ), não podendo ninguém, muito menos o professor, ser privado de direitos por motivo de crença religiosa ou de convicção filosófica ou política (art. $5^{\circ}$, VIII, da CF/88).

Quando se diz que o professor, mais que outra qualquer profissão, dever ter assegurada a manifestação do pensamento intelectual e científico, esta afirmação também está expressa na Constituição em mais outro dispositivo, art. 206, III, da CF/88, em que é um dos princípios da educação brasileira o pluralismo de ideias e de concepções pedagógicas.

Por fim, além de ser direito do cidadão e do professor se ver livre da censura deste projeto, também é um direito das instituições de ensino superior, como já dito anteriormente, 
nos termos do art. 207, da CF/88: "as universidades gozam de autonomia didático-científica, administrativa e de gestão financeira e patrimonial”.

\section{Considerações finais}

A ideia do projeto de lei "Programa Escola sem Partido", inegavelmente, integra as atuais ações governamentais truculentas que visam aniquilar as incipientes experiências democráticas participativas, primando, sobretudo, pelo fim da escola pública, pelo silenciamento do professorado, e pela desarticulação dos mecanismos e espaços democráticos da sociedade brasileira.

Fruto de contramovimento autoritário em oposição à mobilização da sociedade brasileira da década de 1980, que teve, esta última, significativa produção científica no campo da educação, e com notória influência dos educadores na Assembleia Nacional Constituinte de 1987/1988 e, posteriormente, na proposta de uma nova LDBEN, propiciando princípios democráticos na gestão da educação pública.

Aproveitou-se da inépcia dos governos que seguiram à promulgação da $\mathrm{CF} / 88$, os quais, no plano ideológico-normativo, pouco se avançou em termos de regulamentação da gestão democrática, possibilitando o avanço autoritário que se mostrou atualmente.

Não havendo o Estado policialesco de outrora, que controlava as ações da sociedade, para que fosse possível a outrora defesa da liberdade formal, a "Escola sem Partido" visa coibir a liberdades da profissão docente, principalmente a liberdade de cátedra e a da difusão da ciência como um todo.

Como a lei pauta o discurso da aplicação do direito, sendo ela o ponto de partida das digressões interpretativas, mesmo quando o direito aplicado dela se afasta completamente (ex., o estado de exceção), depois de perder o monopólio do Poder central por mais de uma década, a ala conservadora, agora restituída ao centro decisório, voltou-se à lei para a legitimação da mudança comportamental que visa implantar, razão de ser do PL nº. 867/2015.

Parte-se de sofismos ideológicos para vender a ideia de que, primeiro, o Estado se conduz sem qualquer influência política, ideológica ou religiosa, portanto, que existe algum Estado neutro nestes aspectos. Segundo, que é possível assegurar aos pais uma educação moral de seus filhos que esteja de acordo com suas próprias convicções, dada à gama de divergências de pensamento, não conseguindo explicar: o que é influência política? Como um Estado se conduz sem influência política?

Destina-se, principalmente, este projeto de lei, a controlar os professores da educação básica da rede pública de ensino, visando à formação da massa pobre dos cidadãos em geral, 
resguardando-se a liberdade de informação dos filhos das elites, na medida em que para estes a própria posição social, em maior ou menor tempo, moldará suas formações e atuares.

Trata-se de um projeto de lei inconstitucional, por atentar várias proposituras constitucionais ( $\operatorname{arts}, 1^{\circ}$, II, $5^{\circ}$, IV, VIII e IX, 205, 206, II, III, VI e VII, e 207, dentre outros dispositivos), o qual, mesmo inconstitucional, não há qualquer tranquilidade para a sua não aprovação, ao contrário, já presenciamos a aprovação de projetos similares em inúmeros municípios da federação brasileira, justamente por ser o direito instrumental de dominação e pacificação social, que tem como fim último a prescrição de comportamentos sociais esperados, em regra, sob pena do atuar violento por parte do Estado.

E, assim sendo, havendo mudança nos fatores reais de poder, como houve recentemente no Brasil, espera-se nova roupagem (revogando, ab-rogando, derrogando e etc.), ou mantendo-se o mesmo figurino para dar-lhe novo sentido (alterações interpretativas, ampliativas, reducionistas, conceituais etc.), nas normas jurídicas, de modo que, no direito, a certeza interpretativa que se tem de uma norma é que a interpretação de hoje pode não ser a mesma de amanhã, necessitando da retomada dos movimentos sociais vanguardistas para o enfrentamento deste temor autoritário que se avizinha e assombra o professorado brasileiro.

\section{Referências}

ARELARO, L. R. G. Resistência e submissão: a reforma educacional na década de 1990. In: KRAWCZYK, N.; CAMPOS, M. M.; HADDAD, S. (orgs). O cenário educacional latinoamericano no limiar do século XXI: reformas em debate - Campinas, SP: Autores Associados, 2000.

BONAVIDES, P. Ciência Política. 10 ed. São Paulo: Malheiros Editores, 1997.

BOllmann, M. G. N. Revendo o Plano Nacional de Educação: Proposta da Sociedade Brasileira. Educação e Sociedade, Campinas, v. 31, n. 112, p. 657-676, jul.-set. 2010. DOI: https://doi.org/10.1590/s0101-73302010000300002.

BRASIL. Câmara dos Deputados. Projeto de Lei n. ${ }^{\mathbf{0}}$ 867, de 2015. Disponível em: https://www.camara.leg.br/proposicoesWeb/prop mostrarintegra;jsessionid=375C 72096A FD87644868A98ED8436064.proposicoes WebExterno2? codteor $=1317168 \&$ filename $=$ Avuls o+-PL+867/2015. Acesso em: 18 agosto de 2019.

BRASIL. [Constituição (1988)]. Constituição da República Federativa do Brasil de 1988. Brasília, DF: Presidência da República, [2016]. Disponível em: http://www.planalto.gov.br/ccivil_03/Constituicao/ Constituiçao.htm. Acesso em: 18 de agosto de 2019.

CIAVATTA, M. Resistindo aos dogmas do autoritarismo. In.: FRIGOTTO, Gaudêncio (Org.). Escola "sem" partido: esfinge que ameaça a educação e a sociedade brasileira. Rio de Janeiro: UERJ, LPP, 2017. DOI: https://doi.org/10.1590/1981-7746-soloo091. 
FONSECA, M. Políticas Públicas para a Qualidade da Educação brasileira: entre o utilitarismo econômico e a responsabilidade social. Caderno CEDES, V.29, No.78, maio/agosto.2009, p.153-177. DOI: https://doi.org/10.1590/s0101-32622009000200002.

FRIGOTTO, G. A gênese das teses do Escola sem Partido: esfinge e ovo da serpente que ameaçam a sociedade e a educação. In.: FRIGOTTO, Gaudêncio (Org.). Escola "sem" partido: esfinge que ameaça a educação e a sociedade brasileira. Rio de Janeiro: UERJ, LPP, 2017. DOI: https://doi.org/10.1590/1981-7746-solooo91.

LEVI, L. Legitimidade. In: BOBBIO et. al. Dicionário de Política. Tradução João Ferreira et. al. 5. ed. Brasília: Editora Universidade de Brasília: São Paulo: Imprensa Oficial do Estado de São Paulo, 2004, p. 675-679. DOI: https://doi.org/10.5433/1679-0359.2021v42n3supl 1p1673.

MANHAS, C. Nada mais ideológico que “Escola sem Partido”. In.: A ideologia do movimento Escola sem Partido: 20 autores desmontam o discurso. Ação Educativa Assessoria, Pesquisa e Informação (Org.), p. 15-21. São Paulo: Ação Educativa, 2016.

NOGUEIRA, M. A.; ROMANELli, G.; ZAGO, N. (Org.). Família e escola: trajetórias de escolarização em camadas médias e populares. Petrópolis: Vozes, 2000. DOI: https://doi.org/10.1590/s1413-24782001000100016.

REALE; M. Lições preliminares de direito. 27. ed. São Paulo: Saraiva, 2002.

SAVIANI, D. O Plano de Desenvolvimento da Educação: análise do projeto do MEC. Educação \& Sociedade, Campinas, vol. 28, nº. 100, p. 1231-1255, out. 2007. DOI: https://doi.org/10.1590/s0101-73302007000300027.

STOPPINO, M. Ideologia. In: BOBBIO et. al. Dicionário de Política. Tradução João Ferreira et. al. 5. ed. Brasília: Editora Universidade de Brasília: São Paulo: Imprensa Oficial do Estado de São Paulo, 2004, p. 585-597. DOI: https://doi.org/10.5433/16790359.2021v42n3supl1p1673. 